Protestantismo em Revista é licenciada sob uma Licença Creative Commons.

http://dx.doi.org/10.22351/nepp.v43i01.2788

\title{
Democracia e fundamentalismo político-religioso
}

\author{
Democracy and political and religious fundamentalism
}

José Neivaldo Souza*

\begin{abstract}
Resumo
O objetivo deste ensaio é refletir, a partir da crise política e econômica vivida no Brasil, sobre o problema da democracia e o uso corrente que se faz deste termo a fim de justificar uma ideologia elitista e conservadora. Em primeiro lugar, pensar a democracia face aos desafios da política brasileira. Em segundo lugar, o quanto o fundamentalismo religioso se aproveita deste momento para se engajar no poder. E por último, abordar o tripé do fundamentalismo político-religioso, revelando sua força diante da opinião popular. Algumas referências ajudarão a pensar este momento, em particular o texto de Norberto Bobbio sobre Qual democracia?
\end{abstract}

Palavras-chave

Democracia. Fundamentalismo. Política. Religião.

\begin{abstract}
The purpose of this essay is to reflect about the political and economic crisis facing Brazil, the problem of democracy and the current use of this term in order to justify an elitist and conservative ideology. Firstly, we should consider the challenges of Brazilian policy and how much the religious fundamentalism takes advantage of this moment to influence in government. And finally, approach the tripod of the political-religious fundamentalism and your strength in the face of popular opinion. Some references will help understand this moment we are facing and in particular the text of Norberto Bobbio on "What democracy?".
\end{abstract}

Keywords

Democracy. Fundamentalism. Politics. Religion.

[Texto recebido em junho de 2016 e aceito em junho de 2017, com base na avaliação cega por pares realizada por pareceristas ad hoc]

* Mestre em Filosofia e Psicologia Clínica. Doutor em Teologia. Professor na Faculdade Evangélica do Paraná (FEPAR) e na Faculdade Teológica Batista do Paraná (FTBP). E-mail: neivaldo.js@gmail.com 


\section{Introdução}

O que é Democracia? O que é fundamentalismo político-religioso? Eis alguns termos que chamam atenção, principalmente nos momentos de crise política e econômica, pela qual passa o Brasil. ${ }^{1}$ Definir o termo democracia não é fácil. A etimologia diz mais de uma utopia do que de uma sociedade real. Torna-se mais complexo ainda sua definição em relação às posturas religiosas e partidárias cujo objetivo é implantar um Estado absoluto em detrimento da liberdade e da igualdade.

Este ensaio se propõe, em primeiro lugar, refletir acerca do tema democracia, seu uso corrente nos momentos de insegurança, medo e expectativa em relação aos rumos da nação, tal como pensar sobre a confusão que se faz entre Democracia e eleição partidária. Em segundo lugar, seguindo a mesma reflexão, abordar o Fundamentalismo e o Estado absoluto. É um tema que chama atenção por identificar algumas posturas políticas e religiosas chamadas de fundamentalistas. Sob esta identificação aparece uma ideologia comum e, ainda que o fundamentalismo religioso faça oposição à sociedade liberal, a ela se submete em razão de interesses comuns. Por fim, pretende trazer à tona o tema do fundamentalismo político-religioso abordando principalmente alguns aspectos comuns à política e à religião. Este tipo de fundamentalismo, ainda que tenha nascido no início do século XX, nos Estados Unidos da América, já se via seus sinais no século XVII a partir do absolutismo hobbesiano. O tripé que o fundamenta tanto serve para as posturas religiosas quanto para as atitudes políticas. Sectarismo, legalismo e dogmatismo são comuns nos dois casos.

À pergunta: o que é democracia e o que é fundamentalismo é o que praticamente esta reflexão, com toda dificuldade, procura responder. Fruto de reflexões publicadas na Biblioteca Ameríndia, uma rede católica (Online) com o espírito ecumênico e aberto ao diálogo, este artigo tem como objetivo refletir sobre o momento atual no Brasil assim como as dificuldades de relacionar teoria e prática; democracia e política; diálogo e fundamentalismo.

\section{A democracia e os desafios da política brasileira}

Há no Brasil, ultimamente, certas manifestações que se orgulham em dizer-se "democráticas". De um lado, os movimentos favoráveis ao governo articulam os partidos a fim de angariar votos de oposição ao Impeachment da presidente, na câmara dos deputados e no Senado; do outro lado, uma oposição que, desde as eleições de 2014 não se conformava com o resultado das urnas e, por conta disso, permaneceram nas ruas e nos palanques pressionando a população a uma oposição cerrada ao governo. A falta de articulação, ou diálogo das lideranças partidárias, causou insegurança e medo em relação aos rumos do governo no país fazendo com que muitos, aliados à base governista, se

1 Este artigo é fruto de notas publicadas no site da Amerindiaenlared, 2016. 
retirassem. Esta situação faz perguntar sobre os rumos da democracia e qual o tipo de regime político está levando o Brasil a tal insegurança.

O termo "democracia", na sua etimologia grega, demos e kracia quer dizer: "poder do povo". Diz respeito a um regime de governo que, pelo Estado de Direito, preza pela soberania popular sobre os poderes legislativo e executivo, protegendo os cidadãos da tirania e da ilegalidade. Ao abordar tal conceito, pode-se dizer que esta teoria não se encarna inteiramente e, na prática, ainda é uma utopia, conforme se constata na história política deste país. A democracia se inspira por alguns valores fundamentais e, entre eles, o maior: a igualdade. Em outras palavras, esta equidade é necessária à cidadania e o filósofo italiano Norberto Bobbio a retrata bem ao dizer que "igualdade não é um fato a ser constatado, mas um dever a ser realizado". ${ }^{2}$

No Brasil, quem governa de fato? Quem toma as últimas decisões? Sob o conceito de democracia, uma classe política, articulada em partidos, busca o poder se distinguindo pelo modo como surge, governa e cai. Pelo "princípio eletivo" esta elite se impõe através de interesses e ideologias comuns, sejam de direita, de esquerda ou de centro. Nesta perspectiva, o eleitor tem a ilusão de que elegeu o seu candidato (vereador, deputado, senador, governador, etc.), sem ter consciência de que nada mais fez senão "confirmar" alguém que, a priori fora "proposto" por uma convenção partidária a qual se exige fidelidade; o candidato, por outro lado, sabe que acima da legitimidade popular está o partido ao qual ele representa e do qual depende.

Este fato pode ser constatado na votação do dia 17 de abril de 2016 sobre a abertura do processo de impeachment da presidente do Brasil, na Câmara Federal. A maioria dos deputados que ali votaram não conseguiu alcançar o "quociente eleitoral" nas eleições de 2014 e, no entanto, estava representando as legendas e coligações partidárias que a colocaram ali. A estatística assusta: dos 513 deputados, apenas 35 se elegeram sozinhos com o voto popular. Traduzindo: atualmente 478 deputados não têm compromisso senão com o partido que os colocou ali. ${ }^{3}$ O Partido do Movimento Democrático Brasileiro (PMDB) articulou sua legenda com 59 votos a favor do processo de impedimento da presidente. Destes deputados, somente 6 conseguiram se eleger sozinhos, ${ }^{4}$ os demais dependeram do rateio da sobra de votos de alguns deputados. Como Partido de centro se compara a um pêndulo que ora pende à direita e ora à esquerda conforme as circunstâncias que lhe são favoráveis. Com a crise política e econômica que favorecia o afastamento da presidente e a vitória de uma elite empresarial conservadora, a convenção do PMDB optou por abandonar os cargos do governo e articular o processo de

2 BOBBIO, Norberto. Qual democracia. São Paulo: Loyola, 2013.

3 CONGRESSO EM FOCO. Disponível em: <http://congressoemfoco.uol.com.br/noticias/so-35deputados-se-elegeram-com-a-propria-votacao>. Acesso em: 18 abr. 2016.

4 EXAME. Disponível em: <http://exame.abril.com.br/brasil/noticias/quem-sao-os-35-deputados-que-seelegeram-sozinhos>. Acesso em: 18 abr. 2016. 
impeachment, antes aceito pelo presidente da câmara, do mesmo partido. Esta estratégia teria como fim a posse do vice-presidente, também do PMDB, como presidente da república. Significa que Dilma Rousseff, eleita com a maioria dos votos brasileiros, apesar de sido "posta" pelo povo em 2014, pode ser "deposta" em 2016 pelos partidos de oposição que comandam a Câmara e o Senado Federal. Diante desta situação salta-se aos ouvidos a pergunta que não quer calar: qual democracia?

Longe de chegar à verdadeira democracia, o que se vê nada mais é senão uma plutocracia, isto é, uma forma de governo onde o poder é exercido por uma elite abastada que manipula os partidos políticos, controla os meios de comunicação em favor dos próprios interesses e usa da liberdade democrática com finalidade de manipular a população e incutir a ideia de que a ditadura ou um regime de linha dura é a melhor solução em momentos de crise. Eis um momento propício para um discurso em favor de um Estado absoluto.

Ainda que a democracia seja uma utopia, não se pode perder a esperança; ainda que a democracia, em sua fase infantil, seja a mais difícil e frágil forma de governo, ela é sem sombra de dúvidas, a melhor forma para o exercício da política. Pode-se concordar com as críticas de Norberto Bobbio e repetir: numa sociedade onde há uma quantidade enorme de partidos, com mais de 35 registrados no STE, o regime democrático é sempre provisório e fácil de ser arruinado pelas ditaduras partidárias. Mas, ainda que seja assim, a democracia é sempre uma utopia pela qual vale a pena lutar, apesar da insegurança e do medo.

O medo é natural ao ser humano. Através dele a pessoa se coloca ao perigo sob duas formas possíveis: lutar ou ceder; viver ou perecer. Há situações em que uma terceira opção parece ser mais evidente: a paralização. A pessoa, transtornada pelo medo, não consegue escapar à letargia, vive na expectativa de que algo ruim vai acontecer, ainda que não haja ameaças reais. O medo, mais que o perigo externo, é um grande complicador na preservação da vida humana em sua dimensão física, psíquica e espiritual.

O medo tem o seu propósito natural: assegurar a sobrevivência, porém, neste tipo de cultura, enfraquecida, ele pode paralisar e tornar-se um produto sobre o qual se investe e se lucra. Zygmunt Bauman 5 chama este investimento de "capital do medo" a ser direcionado a qualquer tipo de mercado que ofereça segurança pessoal, seja econômica, política ou religiosa.

Numa sociedade onde a salvação é individualizada, a segurança pessoal torna-se um produto indispensável ao mercado e, com isso, não é difícil entender o porquê da grande demanda de seguros de vida. Aquilo que seria um benefício à família do falecido, transforma-se num produto sobre o qual lucram grandes seguradoras e não é diferente com os planos de saúde.

5 Cf. BAUMAN, S. Vida líquida. Rio de Janeiro: Zahar, 2009. 
Cresce no Brasil o transtorno psíquico do pânico. Pode-se identificar algumas causas desta síndrome: a ameaça de um mundo competitivo, individualista e sem laços reais; a violência nas casas e nas ruas e sua difusão nos meios de comunicação social, as injustiças sociais e outras. Muitos buscam se libertar, através de psicoterapias, drogas psicotrópicas, porém os que mais sofrem são os pobres. Carentes de possibilidades, eles não têm como comprar remédios ou pagar consultas médicas e psiquiátricas e, por conta disso, procuram igrejas que "supostamente" os atendam gratuitamente.

O mercado religioso, neste sentido, se apresenta como uma opção nesta realidade tão confusa e insegura. Na perspectiva da "fé positiva", o fiel exorciza o seu medo tomando posse dos bens espirituais, apresentados por alguns pastores ou líderes de "confissão positiva", adeptos da Teologia da Prosperidade. Estes bens são os frutos do Espírito Santo: segurança, saúde e riqueza são produtos da oferta/procura no mercado espiritual.

Este cenário é propício para incrementar discursos moralistas de teor salvífico como é o discurso de muitos parlamentares apoiados pela "bancada evangélica". A situação de insegurança e medo, em relação aos rumos econômicos do Brasil, favorece o discurso de salvação que, teoricamente parece conservador, mas na prática é neoliberal. Karl Marx alertara sobre isso ao observar que o surgimento da livre concorrência e das individualidades acarretaria em enfraquecimento e destruição dos laços sociais responsáveis pelo fortalecimento dos valores essenciais à vida.

Este discurso carrega, juntamente com as "promessas" de salvação, o incentivo ao medo e à insegurança pessoal, comparado ao mágico que, antes de tirar da cartola o coelho, o esconde lá, sem que os espectadores percebam. Este discurso aparece na apologia ao "impeachment". Setores do poder econômico, político e religioso se manifestam e faz veicular, nos Meios de Comunicação de Massa, a ambiguidade deste discurso. Aliás, deste tipo de trabalho depende, em grande parte, o êxito na audiência de uma emissora. O que se vê em algumas transmissões televisivas é, parafraseando Bauman, o "povo-ovelha" sendo protegido de "corruptos-lobos" por "policiais-cães pastores".

O "capital do medo", junto às promessas de salvação, é um bom investimento numa realidade onde se cultiva o individualismo e o "exótico liberalismo neopentecostal". Na cultura do medo e da salvação, o indivíduo se vê motivado a acumular sem medida, porém sabendo da fragilidade do "ter" e da possibilidade de tudo perder. Uma cultura da insegurança traz prejuízos à nação, mas, dependendo do ponto de vista, para muitos é uma forma lucrativa, pois há uma vasta produção do medo sobre o qual a população oferece o seu sacrifício. Seja o medo do caos econômico, da desorientação política e religiosa, sempre surgirá um "messias" disposto a salvar e outro pronto a ser sacrificado. 


\section{O fundamentalismo e o Estado absoluto}

Uma cultura baseada no poder, no lucro, na insegurança e no medo engendra uma leitura fundamentalista da vida. O fundamentalismo, segundo o pensador J. Habermas, é um fenômeno cultural exclusivamente moderno. Ainda que tenha uma linguagem religiosa-protestante pode-se situá-lo no início do século XX e identificá-lo na política, na economia, na religião e outras formas de expressão cultural.

A realidade atual apresenta uma globalização de mercados sem limites e, ainda que as pessoas busquem autonomia e liberdade na construção de uma sociedade justa e próspera, o modelo de Estado que se propõe ainda é o "absoluto", isto é, baseado no cerceamento da liberdade, no aparelho militar, no serviço secreto e na implantação de uma moral de usos e costumes que venham a uniformizar o pensamento e a prática do "bem".

Eis um paradoxo: de um lado a livre concorrência, o liberalismo econômico e social se impondo através da circulação de capital, de mercadorias e de pessoas; do outro, a imposição de limites principalmente no que se refere à liberdade humana e à concepção do bem e do mal. De um lado, a realidade capitalista, do outro, a ideologia fundamentalista que "parece" fazer bem tanto à política quanto à economia e à religião. $\mathrm{O}$ fundamentalismo político-religioso quer um Estado novo sob métodos antigos. ${ }^{6}$

Com muita cautela, pode-se situar a base moderna do fundamentalismo no século XVII a partir da obra do filósofo Thomas Hobbes: O Leviatã.7 A ideia de um Estado absoluto vai se fortalecer na "desconfiança" do ser humano em relação à liberdade e à capacidade de fazer o bem. Hobbes argumentava que a natureza humana é má e, por conta disso, a vida em sociedade seria inviável se não houvesse um Estado autoritário que construir e impor suas leis em favor da boa convivência entre os homens. As leis seriam a expressão de um pacto, ou um acordo entre os cidadãos no que se refere à renúncia da liberdade e à construção de um paraíso sem selvageria na terra.

A pessoa aceita este acordo conferindo, modernamente, um caráter absoluto ao seu modo de vida em favor de uma sociedade mais justa. De forma assincrônica adota uma postura livre por conta das exigências contemporâneas, porém não tão livre por razões de lei e de ordem. Em outras palavras: numa realidade globalizada, onde se exige muita liberdade em relação ao diálogo e à tolerância, há um retorno aos acordos vigiados por lei em detrimento do exercício da liberdade. É a partir desta postura, fechada, que se exclui toda possibilidade de interpretação acerca das coisas naturais e sobrenaturais. No fundo, é um bom espaço para que uma elite exerça o seu poder e decrete, ainda com prejuízos à democracia, o que é bom ou mau à sociedade.

\footnotetext{
HABERMAS, Jürgen. Fé e saber. São Paulo: UNESP, 2013. p. 3-4.
}

HOBBES, Thomas. O Leviatã. São Paulo: Martins Fontes, 2003. 
Em relação à religião, o fundamentalismo é mais recente e pode-se situá-lo no início do século XX. Nasce nos EUA como uma teologia de oposição às tendências modernas liberais da Europa. Teólogos evangélicos conservadores, numa reunião em Niagara Falls, em 1895, confeccionaram um texto com os pontos "fundamentais" de sua teologia em relação à verdade. Um destes pontos era a afirmação absoluta da lei de Deus. Este devia ser divulgado e imposto não só nas igrejas evangélicas, mas também na vida pública. Sob uma série de volumes com o título The Fundamentals esta teologia se espalhou entre os anos 1909 a 1925.

O fundamentalismo sustenta uma tese exclusivista. Conserva a tradição oral ou escrita prezando-se mais pelo real, representado no dogmatismo e no cânone bíblico, do que pelo simbólico revelado em atitudes de abertura e diálogo em relação ao diferente. É uma postura que busca esconder uma dualidade latente: de um lado, o conservadorismo em relação às leis de Deus, não porque as interpreta em favor da comunidade, mas porque facilita a manipulação da liderança em relação à verdade divina; do outro lado, a liderança religiosa introjeta estas leis para depois projetá-las pregando a obediência dos fiéis a seu favor e a favor do seu grupo. Este discurso, ainda que negue "este mundo", não renuncia à "posse deste mundo". Max Weber indicava, nesta direção, que os protestantes não tiveram nenhuma dificuldade em se adaptar ao sistema de produção capitalista. ${ }^{8}$

O fundamentalismo político e o fundamentalismo religioso, dependendo da demanda social, dão-se as mãos em favor de um Estado absoluto. Isso se pode constatar na história do Brasil. Os missionários norte-americanos, quando chegaram por aqui, se depararam com os imigrantes europeus, trabalhadores rurais e urbanos, de vasta experiência política e sindical, mas sem nenhuma formação religiosa. No confronto, os missionários pregavam a "submissão" às leis patronais e a um governo ditatorial. Em detrimento da participação nos lucros, apoiavam a privatização e a compra, quase escravizada, da força de trabalho. "A partir do Estado Novo, o movimento pentecostal se fortaleceu por sua tendência individualizante e pela privatização dos bens naturais e sobrenaturais ligados aos dons do Espírito Santo". ${ }^{9}$ Assim, ao mesmo tempo em que procuravam livrar a igreja isolando-a da vida social, justificavam um sistema neoliberal em que o mundo, através de uma cultura determinada, é quem dá as cartas.

O fundamentalismo vai se firmar num período da história em que há algumas ameaças à segurança do continente americano: a primeira guerra mundial e a ascensão dos bolchevistas no poder soviético. Face a esta realidade, os protestantes mais conservadores vão detectar as forças do mal e através de seus pregadores apresentarem os Estados

8 Para uma leitura da obra de Max Weber: WEBER. Disponível em: <http://www.nesua.uac.pt/uploads/uac_documento_plugin/ficheiro/8db98cff48151daf946fe625988763 bfb0737c7e.pdf>. Acesso em: 08 abr. 2016.

9 SOUZA, José Neivaldo. O Discurso da fé e o mercado religioso. Cenáculo, 54, 205, 2015. p. 32. 
Unidos da América como nação messiânica a partir da qual será exorcismado todo mal no Ocidente.

Atualmente, o quadro político-econômico-religioso no Brasil é o lugar propício para os movimentos de tipo fundamentalistas. Assistem-se, em tempos de crise econômica, de insegurança política e desconfiança no ser humano, as articulações em prol de um Estado absoluto. A Frente Parlamentar Evangélica da Câmara dos deputados conta com mais de 92 deputados e seus interesses, no discurso, se apresentam em nível moralista, juntamente com muitos parlamentares que, apesar de optarem por um Estado laico, cultivam uma postura conservadora. Eles almejam um Estado a partir de uma leitura literalista da Bíblia, regra de fé e vida. Sabe-se que na prática a teoria é outra: buscam isenções fiscais, liberdade de expressão e monopólio nos grandes meios de comunicação social; suas igrejas, muitas vezes, são verdadeiros celeiros de lavagem de dinheiro; apóiam o governo até que seus interesses não sejam ameaçados e que siga sua agenda conservadora e se isso não acontece, são incapazes de diálogo e reflexão, articulam uma forte oposição principalmente no que se refere a questões ligadas à tolerância racial, sexual e social. A maioria, com pendência na justiça, por corrupção eleitoral, sonegação fiscal e formação de quadrilha, busca um Estado absoluto que instaure um paraíso segundo sua própria verdade. Neste sentido se pode concordar com os mestres da suspeita: Nietzsche, Marx e Freud quando trata de uma religião que projetam uma imagem de Deus para justificar os próprios interesses, sejam eles morais, sociais ou psicológicos. Não passa de uma ilusão ou de instrumento a serviço do poder.

O fundamentalismo não quer abolir o Estado, mas sim resgatar o fundamento aboluto da ordem numa sociedade em que se preza pelo Estado livre e laico. Contra o pluralismo político ou religioso, os fundamentalistas recorrem à democracia, sem serem democráticos, a fim de usarem da liberdade para a crítica e o desmonte de um determinado governo, ainda que este exerça seu poder justificado pelo voto popular. Eles querem um Estado puro e santo que represente uma única verdade e que não tolere o relativo, próprio da modernidade. O Estado, nesta concepção, deve ser representado na figura de um Messias detentor da lei e da ordem e se não chega pelas eleições, provavelmente vai chegar pela imposição e a ditatura dos partidos que contemplam o tipo de ideologia fundamentalista.

\section{O tripé do fundamentalismo político-religioso}

O fundamentalismo político-religioso se sustenta sobre uma estrutura cujo tripé é bem conhecido nos meios políticos, jurídicos e religiosos: sectarismo, legalismo e dogmatismo. Estes poderes se assemelham quando se trata de um interesse comum e isso não é novidade quando se faz uma leitura dos evangelhos de João (Jo 18.12-14; 19.13-15) e de Lucas (Lc 23.11-12) sob uma hermenêutica crítica e atualizada. 
A distinção dos termos sectarismo, legalismo e dogmatismo, o tripé do fundamentalismo político-religioso, parece ser uma tarefa difícil para quem teoricamente vive num Estado leigo e que, na prática, tem que conviver com a pressão de religiosos, arautos de uma moral conservadora no que se refere ao "ser", mas ultraliberal no quesito "ter". Os evangelhos de João e Lucas ajudam a identificar, na história judaico-cristã, a tentativa de formar um pensamento único na relação política e religião, em vez de uma postura de diálogo e abertura.

No evangelho de João há uma cena pitoresca: um destacamento da Polícia Romana, sob um comandante, juntamente com os guardas dos judeus, leva coercitivamente um homem cujos ideais de poder se diferem dos judeus e romanos. Jesus de Nazaré é amarrado e levado à cúpula dos judeus que, sob um rito sacrificial, acreditava ser o "bem" para a sociedade o sacrifício de um em favor da tranquilidade de muitos (Jo 18.14). Depois de julgado, sob o chefe dos sacerdotes, Caifás, genro do sumo sacerdote Anás, Jesus é conduzido a Pilatos, o procurador da Judeia, nomeado pelo imperador romano Tibério. Sob as ameaças dos judeus: "se deixares esse homem livre, não és amigo de César" (Jo 19.12), Pilatos questiona o povo sobre o poder real de Jesus e a resposta vem de forma inusitada: "não temos rei, senão César" (Jo 19.15). Na narrativa de Lucas, Pilatos partilha esta responsabilidade com Herodes, o soberano das províncias, que depois de muito escárnio sobre o carpinteiro de Nazaré, o envia de volta ao Pretório a fim de receber o veredicto de morte. Naquele dia, como narra Lucas, “Herodes e Pilatos, que até ali eram inimigos, tornaram-se amigos" (Lc 23.12).

O texto está posto. A realidade religiosa se mostra claramente a partir de uma religião cuja liderança é radicalmente política. Em primeiro lugar, os sacerdotes deviam obediência a César, assim como Herodes e Pilatos, por vários motivos e alguns deles são claros: gozavam de privilégios principalmente relacionados à isenção de impostos, às reformas do Templo e às construções de sinagogas; em segundo lugar, os sacerdotes eram partidários e, geralmente apoiavam o partido conservador, herodiano, responsável por manter a ordem e controlar os poderes na Judeia e na Galileia; em terceiro lugar, o pecado era uma mercadoria importante no mercado da fé, pois em torno dele girava as trocas e compras de animais para os sacrifícios de arrependimento. Em outras palavras, o mercado da fé gerava boa receita ao Estado e consequentemente ao governo.

A interpretação da Torá se encaixava aos interesses do Templo e a uma elite controladora da fé. O rigor da Lei interessava aos interessados no poder. Por exemplo: ao imperativo da lei: "adorarás somente o teu Deus" se impunha a adoração a César; ao Messias, esperado pelo povo judeu, impunha-se outra figura, Herodes, considerado o ungido com poderes de salvar ou destruir (como o fez com João Batista); ao ensinamento profético "Deus não quer sacrifício e sim misericórdia" (Os 6.1) a lei pervertida e entendida como: "Deus quer sacrifício, não misericórdia". 
Nesta situação, as ideias de Jesus, acerca da fidelidade a Deus, do amor ao próximo e da construção de um Reino de Justiça, foram perseguidas e colocadas na cruz, como revolucionárias. Jesus não podia exaltar Deus como o único digno de poder; não podia se apresentar como o ungido, anunciado pelos profetas antigos, a fim de libertar os pobres, os doentes e os que sofrem qualquer tipo de opressão (Is 61.1-2) e tampouco podia condenar os sacrifícios. No entanto, Jesus denunciou com a vida as artimanhas maléficas do poder político-religioso.

Jesus se opôs aos poderes que, a um só tempo, eram conservadores, em relação à Lei romana e à Torá, e liberais no que tange aos interesses do poder e da riqueza; distinguiu as divindades, antes confusas sob César e Deus: "dê a César o que é de César e a Deus o que é de Deus" (Mt 22.21; Mc 12.17; Lc 20.25); colocou-se na missão de ungido, o Messias, anunciado pelos profetas e sacerdotes, mas nunca revelado de forma tão clara. Com isso, Jesus se opôs a Herodes que, em nome do pai, exercia abuso no poder, sustentando a opressão aos mais pobres e a escravidão dos mais miseráveis. Jesus advertiu à população quanto ao "fermento dos fariseus e de Herodes" (Mc 8.15); denunciou os sacrifícios no Templo, uma atitude nada favorável ao cuidado alheio ou à libertação pessoal (Jo 2.14-19).

Jesus agiu de tal sabendo que as consequências viriam inexoravelmente e, no entanto, renunciou aos benefícios e se colocou ao lado dos mais desfavorecidos apresentando uma interpretação mais justa e solidária das Leis (Lc 6.9; Mc 2.27;). Ele combateu, com seus ensinamentos e com sua vida, o fundamentalismo político-religioso sustentado pelo tripé: sectarismo, legalismo e dogmatismo.

O que hoje se vê, de maneira particular no Brasil, não se diferencia dos primeiros séculos da Igreja. O sectarismo é uma palavra religiosa, diz respeito a uma postura fechada em relação a outras confissões religiosas, mas pode ser entendido, em nível político, como partidarismo por sua postura em relação a outras ideias e possibilidades de articulação de governo e de Estado. Do ponto de vista político-religioso, os partidos podem se transformar em seitas e vice-versa se a submissão ao capital econômico torna-se o carro-chefe de seus projetos.

$\mathrm{Na}$ perspectiva fundamentalista, a preocupação com a prosperidade individual aparece desvinculada da prosperidade planetária, algo inconcebível, do ponto de vista ético, tanto na comunidade de fé quanto numa cultura de valores. O sectarismo e seu irmão gêmeo o partidarismo têm como objetivo o jargão romano: divide et impera. Apóiamse numa ideologia segundo a qual a eleição e a salvação são exclusivas de um pequeno grupo incapaz de adaptar seus dogmas ao saber laico e social, pois carece de participação popular.

O legalismo, também nesta vertente, interpreta as leis civis e as orientações bíblicas segundo a letra. As leis são importantes para o exercício de "qualquer" governo, 
mas pode funcionar como artifício para auxiliar as lideranças na luta pelo poder e no controle das pessoas.

O dogmatismo, semelhante aos anteriores, diz respeito à obediência ingênua a uma verdade absoluta, indiscutível e inquestionável. Do ponto de vista da inerrância religiosa reage a qualquer moral que se funda em bases laicas. Mais do que se deixar provocar pela Bíblia ou pelo edifício histórico, construído pela teologia cristã, uma postura dogmática lê o texto sagrado segundo um pensamento já predeterminado e, geralmente, sua leitura está ligada à insegurança pessoal e à prosperidade material. Do ponto de vista político, o dogmatismo não se adequa a um Estado constitucional democrático, seus seguidores preferem o absolutismo a qualquer abertura de participação popular no poder.

\section{Considerações finais}

Uma religião cristã que se diz profética é capaz de enxergar estes sinais e aprender com Jesus. Habermas diria que a fé precisa ser aberta não só ao modus operandi do mundo moderno, mas a um "impulso reflexivo" sem o qual a crenças religiosas desenvolvem um potencial destrutivo em sociedades modernas que crescem impiedosamente. O Espírito Santo que em Isaías (61.1-2) ungiu a comunidade profética para libertar os cativos e em Jesus se manifestou revelando um reino de misericórdia é o mesmo que motiva a Igreja hoje a se abrir ao mundo, a aderir ao processo de secularização, a fim que seja implantado e construído, ainda nesta terra, o Reino de Deus e sua justiça (Mt 6.33). Não haverá uma transformação política enquanto houver um fundamentalismo com vistas a um Estado absoluto, construído sob as ditaduras do sectarismo, do legalismo e do dogmatismo, sejam elas políticas ou religiosas.

Uma reforma política exige também que se esclareçam as fronteiras entre o político, o econômico e o religioso, porém sem perder de vista o fim que move toda pessoa em busca de um Estado democrático: igualdade de liberdade e direitos. Norberto Bobbio define democracia não em relação aos meios eletivos, mas ao fim, isto é, à igualdade entre as pessoas. Fazendo uma relação entre democracia e religião, Bobbio prefere uma fé mundana a uma fé sectária, legalista ou dogmática. Invés de uma "democracia" da fé, a fé na democracia: "fé que nos sustenta na construção do mundo humano". ${ }^{10}$

Observando o quadro político no Brasil, é importante perguntar que tipo de democracia se tem e que tipo de democracia se quer. Há uma democracia do tipo teórica que justifica qualquer prática de corrupção e injustiça, já bem conhecida nos meios políticos e há outra democracia na práxis que, apesar de distante, presa pela liberdade e igualdade social. Esta, independente das ações partidárias, sua motivação está nas pessoas de boa vontade.

10 BOBBIO, 2013, p. 40. 


\section{Referências}

BAUMAN, S. Vida líquida. Rio de Janeiro: Zahar, 2009.

BOBBIO, Norberto. Qual democracia. São Paulo: Loyola, 2013.

CONGRESSO EM FOCO. Disponível em:

$<$ http://congressoemfoco.uol.com.br/noticias/so-35-deputados-se-elegeram-com-apropria-votacao>. Acesso em: 18 abr. 2016.

EXAME. Disponível em: <http://exame.abril.com.br/brasil/noticias/quem-sao-os-35deputados-que-se-elegeram-sozinhos>. Acesso em: 18 abr. 2016.

HABERMAS, Jürgen. Fée saber. São Paulo: UNESP, 2013.

HOBBES, Thomas. O Leviatã. São Paulo: Martins Fontes, 2003.

SOUZA, José Neivaldo. O Discurso da fé e o mercado religioso. Cenáculo, 54, 205, 2015.

WEBER. Disponível em:

<http://www.nesua.uac.pt/uploads/uac_documento_plugin/ficheiro/8db98cff48151daf 946fe625988763bfb0737c7e.pdf >. Acesso em: 08 abr. 2016. 